\section{Public Health Review - International Journal of Public Health Research}

\title{
Assessment of patient satisfaction with inpatient services at secondary level setting
}

\author{
Saravanakumari A D. ${ }^{1}$, D. Thamarai Selvi. ${ }^{2}$, Rajesh Kumar R. ${ }^{3 *}$, Paul S. \\ DOI: https://doi.org/10.17511/ijphr.2020.i06.03 \\ 1 Saravanakumari Arumugham Dhanaraj, Assistant Professor, Department of Community Medicine, Government Villupuram Medical College, \\ Villupuram, Tamil Nadu, India. \\ 2 D. Thamarai Selvi, Associate Professor, Rajah Muthiah Dental College, Chidambaram, Tamilnadu, India. \\ 3* Ramasamy Rajesh Kumar, Research Scientist, College of Agriculture and Biotechnology, Zhejiang University, Hangzhou, China PR. \\ 4 Sayan Paul, Research Scholar, Department of Biotechnology, Manonmaniam Sundaranar University, Tirunelveli, Tamil Nadu, India.
}

Background: Continuous quality improvement is linked to the use of timely and useful feedback from clients. Patients constitute the hospital's direct clientele. The overall satisfaction is an important aspect of the service itself and it is considered to be an important outcome measure for health services. Patient care is not considered to be of high quality unless the patient is satisfied. Objective: To assess the level of satisfaction with available health services among inpatients attending secondary level hospital. Methods: A cross-sectional study was conducted using pretested, semi-structured questionnaire among 100 inpatients attending Government Hospital Chidambaram, Tamil Nadu. Systematic random sampling was used. Results: 96\% participants were satisfied with the attitude of doctors and nurses, $80 \%$ were highly satisfied with the cleanliness of hospital campus, $82 \%$ were highly satisfied with lab services, $83 \%$ satisfied with food services. $92 \%$ were satisfied with the speedy admission to the ward, 74\% satisfied with the ward facilities. $86 \%$ gave a neutral response for other amenities,26 \% satisfied with a drinking water facility. Overall satisfaction among inpatients was a mean of 3.9 out of 5 (78\%). Socio-demographic characteristics were not significantly related to overall satisfaction scores. Conclusion: Patients were generally satisfied with the hospital facilities. Patients input on various deficiencies needs to be addressed by the hospital leadership to achieve consumer delight.

Keywords: Patient satisfaction, inpatient services, Secondary level Hospital, Quality medical care

Corresponding Author

Ramasamy Rajesh Kumar, Research Scientist, College of Agriculture and Biotechnology, Zhejiang University, Hangzhou, China PR.

Email: iamramrajesh@gmail.com
How to Cite this Article

To Browse

Saravanakumari AD, Selvi DT, Kumar RR, Paul S. Assessment of patient satisfaction with inpatient services at secondary level setting. Public Health Rev Int J Public Health Res. 2020;7(6):58-65. Available From

https://publichealth.medresearch.in/index.php/ijphr/ article/view/142

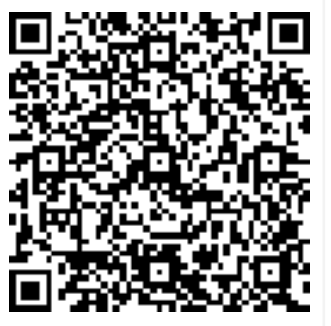

Manuscript Received 2020-11-01

Conflict of Interest No

Review Round 1
2020-11-11
Funding
Nil
2020 by Saravana kumari Arumugham Dhanaraj, D. Thamarai Selvi, Ramasamy Rajesh Kumar, Sayan Paul and Published by Attribution 4.0 International License https://creativecommons.org/licenses/by/4.0/ unported [CC BY 4.0].
Accepted 2020-12-23 


\section{Introduction}

Health care system in the world is moving from a set of purely provider-based systems to receiverbased systems. In this regard, patients' satisfaction is an essential component of quality assessment. Quality care is one of the central dimensions of public health. Good quality care needs to be delivered at the earliest and at the proper time which is a basic right of consumers. Quality care can be divided by measurement into Structure, Process and Outcome.

Structure refers to basic infrastructure and the overall facility, Process means the way the care is delivered and Outcome points to the final result. Health care must guarantee quality care along with safety which is pivotal to quality care. In the present scenario where the hospital is recognized as a social institute and the patient is the only reason for its existence, the hospital must strive for patient-oriented services [1].

Over 50 years, an overwhelming number of publications on the topic have appeared. At first, research focused on patient satisfaction as a condition to be satisfied to reach desirable clinical outcomes, such as appointment keeping or compliance with recommended treatment.

Gradually, interest shifted to patient satisfaction as a dependent variable. Nowadays, hardly any hospital will fail to incorporate in-patient satisfaction rating into their evaluation of care [2]. Selecting the health care and measuring its quality is very complex and has remained elusive yet the tools of its measurement have increasingly improved.

Many factors including poor systems and stress of the caregivers affect the quality along with the satisfaction of patients. Patient satisfaction denotes the extent to which the general health care needs of the clients are met to their requirements.

Patients carry certain expectations before their visit and the resultant satisfaction or dissatisfaction is the outcome of their experience. A simple and practical definition of satisfaction would be the degree to which desired goals have been achieved. It is a perception and an attitude that a consumer can have or view towards a total experience of health care. It comprises both cognitive and emotional facets and is influenced by previous experience, expectations and social networks.
Patient expectations of care and attitudes towards health care system greatly contribute to satisfaction; other psychosocial factors, including pain and depression, are also known to contribute to patient satisfaction scores [3].

A better appreciation of the factors about client satisfaction would result in the implementation of custom made programs according to the requirements of the patients, as perceived by patients and service providers.

It has also been reported that the interpersonal and technical skills of health care providers are two unique dimensions involved in patient assessment of hospital care [4]. Customers are educated and are demanding that their needs are met. In the ideal service environment, It is not just important to meet the customers' needs but to "delight" the customer.

Health professionals are also benefited and guided by the outcome of these surveys. The feedback received is likely to help them in identifying potential areas for service improvement. The ability to satisfy patients is vital for many reasons. It is mainly helpful for hospitals to establish a patientoriented quality health service rather than focusing only on the patient's disease. Improvement in the service quality involuntarily uplifts the reputation gained by the health care institution.

Patient satisfaction is also a valuable competitive tool, to increase staff motivation. Recent research has shown that service satisfaction can significantly enhance patients' quality of life. Further awareness among medical practitioners on the effect of patient characteristics over patient satisfaction will enable the provision of patient-oriented health care, satisfying both the health care provider and the patient. It will help strengthen patients' trust and confidence in the health care professional [5].

There are various methods for assessing patient's satisfaction including using electronic forms, phone calls, and face to face interviews with patients. Performing the Satisfaction Survey using a questionnaire has the features of posing more questions, reducing the possibility of bias, and also cost-effectiveness.

This study was therefore undertaken to evaluate the level of patient satisfaction related to different parameters of quality health care 


\section{Materials and Methods}

A cross-sectional study was conducted in Government Kamaraj secondary level hospital in Chidambaram town serving a population of 63701 in Tamil Nadu. This hospital is a 231 bedded hospital with an outpatient strength of 1638 per day, inpatient about 183 per day, referral in 110 and referral out of 89 per month.

\section{Questionnaire}

A pre-tested, semi-structured questionnaire was designed based on the literature review, standardized by a small scale pilot study on 50 patients. The questionnaire contained part 1 and part 2. Part 1 contained questions on sociodemographic characteristics and part 2 contained questions on 28 items that measure six core dimensions on patient satisfaction. The wellrecognized dimensions are facilities in the ward, doctor's and nurse's attitude, communication, responsiveness in the ward, hospital food services, laboratory services, cleanliness of the hospital, basic amenities, improvement, and willingness to recommend.

The questionnaire consisted of five-point Likert scale items. Responses to the variables in the questionnaires were assigned a score of 1 for 'highly dissatisfied', 2 for 'dissatisfied', 3 for 'neutral', 4 for 'satisfied' and 5 for 'highly satisfied'. Mean analysis was carried out on individual factors. A mean of 5 was classified as highly satisfied, 4 as satisfied and remaining was classified as neutral with the service provided.

\section{Sample size determination}

In a pilot study out of 50 patients interviewed, 36 of them were highly satisfied in all facilities available in the hospital.

Keeping this as prior information, the sample size has been calculated using

$N=Z 21-a / 2 P \times(1-P) /(\Sigma P) 2$

Where $\mathrm{p}=$ proportion of the satisfaction level $(72 \%)$ $a=5 \%$ and $\Sigma=$ relative precision as $10 \%$.

The required sample size has been 100 .

A total of 100 inpatients aged above 18 years who got admitted from February 2015 to April 2015 were the study population.
Inclusion criteria: Patients aged above 18 years of both gender who got admitted and stayed in the hospital in the general ward for more than 3 days.

Exclusion criteria: Patients from paediatric, psychiatric, Dental, Antenatal care and Postnatal care units were excluded in this study. Emergency cases and medico-legal cases were excluded.

Systematic Random Sampling: Every third patient admitted in the general ward was being selected for the study.

The survey was carried out twice weekly. Prior approval of the ethical board was obtained before beginning the survey. Permission from the District Joint director of health services and the chief medical officer was obtained before the survey was carried out in the hospital. Informed verbal consent was taken from all the participants before the start of the interview. Doctors and the supporting staffs were largely kept unaware of the survey, except in unavoidable circumstances, to avoid the bias in their behaviour with the patients.

Respondents were assured of confidentiality. All respondents were encouraged to express their opinion freely and fairly. Precautions were also taken to obtain unbiased results. Schedules are explained by the researcher personally in a vernacular language and were filled by her personally. Since the investigator herself carried out the survey, there was no problem of observer variation as far as the study is concerned.

\section{Analysis}

The surveyed questionnaires were collected and coded in the MS Excel database and analyzed using SPSS version 20. Descriptive statistics were performed on socio-demographic variables. The satisfaction score was expressed as the mean and standard deviation for overall satisfaction with the health services.

\section{Results}

A total of 100 patients from the inpatient department were included in the study. It was observed in the present study, out of 100 in patients distribution among the study subjects were equal. $34 \%$ of inpatients belong to the age category of $30-$ 45 years. $33 \%$ of respondents were illiterates. $5 \%$ were graduates indicating higher educational status. Majority of the subjects (89\%) were married. 
Regarding occupation, 59\% belonged to the unskilled group. $48 \%$ of participants belonged to families having monthly income less than 3000. Recording the place of residence, data shows that the majority (95\%) of the patients were from rural areas (Table-1). $90 \%$ of inpatients came to the hospital of their own and $10 \%$ of patients were referred into the hospital.

Table-1: Socio Demographic profile of Inpatients (IPD) $(n=100)$.

\begin{tabular}{|c|c|c|}
\hline \multicolumn{2}{|c|}{ Characteristics } & No of subjects (\%) \\
\hline \multirow[t]{2}{*}{ Sex } & Male & $50(50)$ \\
\hline & Female & $50(50)$ \\
\hline \multirow[t]{5}{*}{ Age } & $18-29$ & $17(17)$ \\
\hline & $30-45$ & $34(34)$ \\
\hline & $46-60$ & $28(28)$ \\
\hline & $61-75$ & $17(17)$ \\
\hline & $>75$ & $04(04)$ \\
\hline \multirow[t]{3}{*}{ Marital status } & Married & $89(89)$ \\
\hline & Single & $08(08)$ \\
\hline & Widowed/separated & $03(03)$ \\
\hline \multirow[t]{2}{*}{ Place of residence } & |Urban & $05(05)$ \\
\hline & Rural & $95(95)$ \\
\hline \multirow[t]{6}{*}{ Education } & Illiterate & $33(33)$ \\
\hline & Primary & $23(23)$ \\
\hline & Middle & $16(16)$ \\
\hline & High school & $14(14)$ \\
\hline & Higher secondary & $09(09)$ \\
\hline & Degree & $05(05)$ \\
\hline \multirow[t]{3}{*}{ Occupation } & Unemployed/dependent & $37(37)$ \\
\hline & Unskilled & $59(59)$ \\
\hline & Skilled & $04(04)$ \\
\hline \multirow[t]{4}{*}{ Family income } & $<3000$ & $48(48)$ \\
\hline & $3001-5000$ & $25(25)$ \\
\hline & $5001-10000$ & $23(23)$ \\
\hline & $>10000$ & $04(04)$ \\
\hline
\end{tabular}

Regarding accessibility, to the hospital, 6\% traveled less than $2 \mathrm{KM}$ to reach the hospital while $40 \%$ came from 11 to $20 \mathrm{KM}$ distance to avail of health care services.53\% of patients traveled by bus to avail themselves of health care services and $12 \%$ came by 108 ambulance services(Table-2). Inquiries about the reasons for selection of this hospital revealed Treatment being good (58\%), fewer expenses / free services (27\%), and doctors' availability $(21 \%)$ were the primary reasons stated by the respondents. Other reasons like emergency services, drugs availability, investigations availability reputation of staffs and government hospital gained less than $20 \%$ satisfaction were not taken into account (Table-2).
Table-2: Factors influencing Utilization of services and Distribution of Patients.

\begin{tabular}{|c|c|c|}
\hline \multicolumn{2}{|c|}{ Characteristics } & No. of subjects \\
\hline \multirow[t]{3}{*}{ Reasons } & Treatment good & $58(58)$ \\
\hline & $\begin{array}{l}\text { Fewer expenses/free } \\
\text { services }\end{array}$ & $27(27)$ \\
\hline & Doctors availability & $21(21)$ \\
\hline \multirow[t]{7}{*}{ Mode of Transport } & By Bus & $53(53)$ \\
\hline & Auto & $13(13)$ \\
\hline & Car & $04(04)$ \\
\hline & Two Wheeler & $16(16)$ \\
\hline & Walk & $02(02)$ \\
\hline & Ambulance 108 service & $12(12)$ \\
\hline & Cycle & $0(0)$ \\
\hline \multirow[t]{4}{*}{ Transport cost(Rs) } & $6-10$ & $11(15.94)$ \\
\hline & $11-50$ & $42(60.82)$ \\
\hline & $51-100$ & 04 (5.79) \\
\hline & $101-1500$ & $12(17.39)$ \\
\hline \multirow{4}{*}{$\begin{array}{l}\text { Time is taken to reach the } \\
\text { facility }\end{array}$} & $<30$ minutes & $50(50)$ \\
\hline & $\mid<1$ hour & $43(43)$ \\
\hline & $1-2$ hours & $07(07)$ \\
\hline & $>2$ hours & $00(00)$ \\
\hline \multirow[t]{5}{*}{ Distance } & $<2 \mathrm{~km}$ & $6(6)$ \\
\hline & $3-5$ & $15(15)$ \\
\hline & $6-10$ & $22(22)$ \\
\hline & $11-20$ & $40(40)$ \\
\hline & $>20$ & $17(17)$ \\
\hline
\end{tabular}

Regarding the speedy admission to the ward, $92 \%$ of the respondents were satisfied. $87 \%$ of the respondents were satisfied with the cleanliness of the ward.

When assessing the respondent's satisfaction with the attitude and practice of health care providers they were asked to indicate if the physician/doctors were courteous, listened to their complaints, took enough time and explained what they wanted to know, and gave them good advice and treatment, $97 \%$ were satisfied with Doctors visit and nurses promptness in answering calls.

$95 \%$ were satisfied by the approach of the doctor during treatment. Regarding hospital diet, $12 \%$ of respondents were highly satisfied and $81 \%$ were satisfied with the quality and quantity of the diet. $85 \%$ were satisfied with the timeliness of serving diet.

Out of 100 inpatients, 78 availed lab services. Among them $97.4 \%$. were highly satisfied with the cleanliness of the lab. $75 \%$ of the respondents were satisfied with the maintenance of toilets. 
Out of 100 patients, 39 were dissatisfied with the drinking water facility, $48 \%$ were satisfied with the parking facility and $100 \%$ gave neutral responses for an ambulance, suggestion box, and blood bank facilities. $95 \%$ were satisfied with health improvement and $97 \%$ were satisfied and willing to recommend the hospital for treatment.

The degree of overall satisfaction level at various services assessed as shown in Table 3. The overall satisfaction score with available services, in general, was a mean of 3.9 out of $5.96 \%$ were satisfied with the doctor's and nurses' attitude. $83 \%$ of respondents were satisfied with the food services.86\% gave neutral responses to other amenities.80\% were highly satisfied with the cleanliness of the hospital campus.82\% were highly satisfied with lab services.74\% were satisfied with ward facilities (Table 3).

There was a high degree of satisfaction $82 \%$ (a mean of 4.81) as far as lab services are concerned followed by satisfaction with the cleanliness of hospital campus $80 \%$ (mean of 4.76 ) and health care providers attitude (mean of 4.04) (Table 3).

Table-3: Mean and SD of overall satisfaction level of facilities in the secondary level hospital.

\begin{tabular}{|c|c|c|c|c|c|c|c|c|c|}
\hline \multirow{3}{*}{\begin{tabular}{|l|}
\multicolumn{1}{|c|}{ Dimensions } \\
Doctors and nurses \\
attitude in the ward
\end{tabular}} & \multicolumn{2}{|c|}{ Neutral } & \multicolumn{2}{|c|}{ Satisfied } & \multicolumn{2}{|c|}{$\begin{array}{c}\text { Highly } \\
\text { satisfied }\end{array}$} & \multirow{2}{*}{ 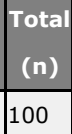 } & \multirow{2}{*}{\begin{tabular}{|l|} 
Mean \\
5
\end{tabular}} & \multirow[t]{2}{*}{ SD } \\
\hline & N & $\%$ & n & $\%$ & $\mathrm{~N}$ & $\%$ & & & \\
\hline & - & - & 96 & 96 & 4 & 4 & 100 & 4.04 & 0.015 \\
\hline Diet & 08 & 08 & 83 & 83 & 09 & 09 & 100 & 4.01 & 0.056 \\
\hline Lab services & - & 1 & 18 & 18 & 82 & 82 & 78 & 4.81 & 0.192 \\
\hline $\begin{array}{l}\text { Cleanliness in the } \\
\text { hospital }\end{array}$ & 3 & 3 & 17 & 17 & 80 & 80 & 100 & 4.76 & 0.466 \\
\hline Other Amenities & 86 & 86 & 13 & 13 & 01 & 01 & 100 & 3.14 & 0.208 \\
\hline Ward facilities & 15 & 15 & 74 & 74 & 11 & 11 & 100 & 3.95 & 0.312 \\
\hline
\end{tabular}

\section{Discussion}

The present study was an attempt to assess the level of satisfaction among inpatients with the available services in the allopathic government health facility. Very few similar studies in secondary care setting have been done and therefore lack the data for comparison is evident.

Yet, the findings of the survey are quite helpful if they are transformed into actions for improving the quality of health care. It can be observed from (Table 2) that the most important motivating factor for the visit to the secondary level health facility was good treatment followed by fewer expenses
( $58 \%$ and $27 \%$ ) what is more critical to learn is that patients felt that the services offered at the private hospitals were unaffordable and beyond their reach. Moreover, a mismatch between the huge amount of money spent and the quality of services received impelled many of them to seek the services of a government hospital.

In almost all the studies, age did not affect the level of patient satisfaction. However, a patient satisfaction study to assess hospital services in Kuwait concluded age as the most important determinant for overall satisfaction [6].

Gender was found to be an influencing factor in studies conducted in Israel, Kuwait and Saudi Arabia. In Israel, a higher level of satisfaction was demonstrated among males [7] concerning females and also in a study done by Ibrahim et al in Kuwait [8]. In contrast, females had significantly higher satisfaction rates in Saudi Arabia [9]. No such significant relationship was observed in the present study.

A total of $89 \%$ of the study subjects were married in the present study. Similar findings $87.2 \%$ in Syed et al. in Haryana, $92 \%$ were stated by Surg et al., $70.6 \%$ in Said Bodur et al. and $65.5 \%$ in Dipanjan et al. Studies showed married people utilize the health facilities more than others $[8,10,11,12]$.

Patients having tertiary education were shown to have significantly lower levels of satisfaction in a study conducted in the United Arab Emirates [13] and Saudi Arabia [9]. Patients from lower socioeconomic groups had higher satisfaction levels. $[14,15]$ Other studies did not show a similar association. As the present study finds, there is a need to focus on education levels of rural people when healthcare services policies are being devised.

A total of $59 \%$ of inpatients belonged to the unskilled employed group. A similar finding was seen in Syed et al. study showed that $(53.55 \%)$ were employed [4]. $48 \%$ of inpatients belonged to families having monthly income less than 3000 which is consistent with the finding $(52.66 \%)$ seen in Syed et al. study [4]. The importance of public healthcare services for those belonging to a lower standard of living index implies that subsidized public healthcare services are a reality and a lifeline for the majority of the population.

Most countries are focusing their attention on the cost and access to health care because it needs to be distributed appropriately and equitably. 
The affordability of the cost involved in reaching the health facility by almost all signifies the readiness of the patients to pay for their health. In the present study, $60.86 \%$ of inpatients spent Rs. $11-50$ for travel which is very similar $(44.75 \%)$ in the study by Andrabi et al [1]. On the other hand, $17.39 \%$ of inpatients spent more than Rs 100 for travel to reach the hospital.

Regarding the place of residence, it was observed that $(95 \%)$ of inpatients were from the rural area which indicates that utilization of health care services by the rural population was very high. Similar finding $(53.9 \%)$ was stated by Sodani et al in his study in Madhya Pradesh [16]. Studies have reported that individuals belonging to urban and rural areas show different patterns of healthcare services utilization [12]. In the context of developing nations, it has been reported that people residing in urban areas have wider access to healthcare services. Those living in rural societies are faced with wider challenges in terms of options available for healthcare services as well as accessing them.

Location of the hospital can determine its utilization pattern. Accessibility in term of time and distance is important for patient satisfaction. Regarding accessibility to the hospital, the present study shows $22 \%$ of inpatients came from 6 to $10 \mathrm{KM}$ distance to avail health care services which is consistent with the study done by Andrabi et al. in Srinagar [1]. $17 \%$ of inpatients travelled more than $20 \mathrm{KM}$ to avail themselves the health care services indicating the faith of the respondents in the quality of services provided. On the contrary, there was a high level of dissatisfaction (84\%) as far as accessibility of health care services observed by Syed et al. in his study in Tertiary Hospital Haryana [4].

Regarding the mode of transport, 53\% of inpatients traveled by bus to avail themselves of health care services in the present study. A similar finding was seen $(79 \%)$ in the study by Andrabi et al [1]. Location and access of the public hospitals have been a major issue emphasized time and again in the state as well as in the nation's plans. Location and access to the hospital was the last priority as perceived by all the patients. What does it indicate? Has increased mobility made access issues irrelevant? Are people ready to travel a greater distance for getting quality services from the medical centres of repute? $10 \%$ of inpatients were referred to the hospital.
This shows that referral from other private or govt. primary health centers were poor or else patients directly came to the hospital for treatment.

$12 \%$ of inpatients travelled by 108 Govt. ambulance to reach the hospital in the present study shows awareness of the public to utilize the emergency services in the District. In the present study out of 100 inpatients, $92 \%$ were satisfied with the speedy admission to the ward. $64 \%$ of the respondents gave a neutral response towards the availability of clean linen and $38 \%$ for the comfort of the given bed.

$34 \%$ of the respondents stated inadequacy of Fans / Lights in the wards. Only $20 \%$ of the patients were satisfied with the timely change of bed sheets was the findings reported by Sumeet et al. [17] in his study in Punjab.

A higher satisfaction level was associated with hospitals at a level lower than district or provincial hospitals. Patients who were admitted to urban hospitals were more satisfied with studies conducted in Sri Lanka [5], China [15], and the United Arab Emirates [13]. The reasons for observing a higher satisfaction in urban hospitals in some countries may be secondary to having better-trained staff, well-equipped technical facilities, and the reputation of the institutions over other hospitals.

If doctors and nurses communicate well with patients and explain what is happening and what to expect, patients react quite favourably and tend to overlook less important aspects of their experiences that may not be as positive.

The present study shows $95 \%$ of the inpatients were satisfied with doctors to visit and $97 \%$ were satisfied with nurse's promptness in answering patients call which is consistent with the study by Sumeet et al. [17] in Punjab tertiary care hospital shows that satisfaction levels regarding the quality of service by nursing and paramedical staff were found to be high as $98 \%$ of the patients started the no. of the nurses as adequate. $83 \%$ of patients affirmed that they were provided medication promptly by the nurses and rated communication/behavior of the nurses as good /pleasant and satisfactory in $23 \%$ and $59 \%$ of the cases respectively, but $18 \%$ of respondents described their behavior as harsh/ rude [17].

In the present study, $81 \%$ of the inpatients were satisfied with the quality and quantity of the hospital diet. 
$85 \%$ were satisfied with the timeliness of serving diet. A study by Sumeet et al. [17] in Punjab tertiary care hospital observed $18 \%$ of the patients, all of them were pregnant females in the obstetrics ward and were provided meals under JSSK.

Concerning the infrastructure and basic amenities in the hospital, $71 \%$ gave a neutral response and $26 \%$ were satisfied with the drinking water facility. $100 \%$ of the inpatients gave neutral responses towards the ambulance, blood bank, and suggestion box facilities. $48 \%$ were satisfied with the parking facility which indicates that inpatients were either not aware of the amenities present or a need to utilize did not arise.

A similar finding was observed in Sumeet et al. [17] study that, $21 \%$ of patients reported unavailability of drinking water, $43 \%$ reported unavailability of toilets/handwashing facility in the wards. $62 \%$ and $40 \%$ were dissatisfied with the cleanliness in the toilets and wards respectively. Around $63 \%$ of the respondents were dissatisfied with the convenience of parking [17].

Regarding the overall cleanliness of the hospital present study observed satisfaction level was found to be high with $80 \%$ which shows the changing attitude and concern towards patients services by the government hospitals which has to be highly appreciated.

The overall satisfaction level of inpatients was found to be a mean of 3.9 could be probably due to the cleanliness of the environment, nursing care, and health improvement that contributes to the satisfaction of inpatients.

\section{Limitations}

The information on the total number of patient satisfaction surveys carried out in Asia is limited. The health sector occupies an enormously important position in ensuring sustainable overall socioeconomic advancement in developing countries. Health provider related factors such as type of hospital, technical and physical facilities and quality of health professional-patient relationship can change patients' satisfaction. Their effects on satisfaction may vary from country to country.

Inadequacies in the health sector lead to a vicious cycle of ill-health and poverty. Therefore, it is important to receive regular feedbacks periodically from the patients' point of view to modify the quality of current health service.

\section{Conclusion}

The response of the patients depends upon their socio-economic profile and perceptions. The majority of the respondents were from a rural area with a low socio-economic status that contributes to the overall satisfaction. Content analysis revealed that the cause of dissatisfaction was poor utilities like water supply, linen, lights, and fans, etc., and poor maintenance of toilets. Infrastructure and architectural corrections need to be made to enhance the comfort and satisfaction of the patients. Hospital managers and staff need to be encouraged in using the Patient Satisfaction Survey (PSS) result in improving the quality of services in the hospitals (inculcate quality culture among the staff) rather than using it as an audit tool in evaluating the performance of the staff or hospitals.

\section{What does the study add to the existing knowledge?}

Patient satisfaction study is a major contribution to knowledge. Only a few studies have been done in secondary care settings that too in government hospitals in the state. The questionnaire, data collection methodology adopted is another contribution to knowledge. The feedback received from the study had made the author identify potential areas for service improvement. Cleanliness of the government hospital premises highly appreciated by patients shows the changing health care system towards patient-oriented quality health services.

\section{Author's contribution}

\section{Dr. Saravanakumari Arumugham Dhanaraj: Concept, manuscript preparation}

Dr. D. Thamarai Selvi: Manuscript preparation

Dr. Ramasamy Rajesh Kumar: Statistical analysis

Dr. Sayan Paul: Proof-reading

\section{Acknowledgement}

Authors would like to thank the respondents for taking part in interviews, sharing their experiences and provided their valuable time. My special thanks are due to the Joint Director of Health Services Cuddalore District and Chief Medical Officer Govt Hospital Chidambaram for provided me constant comfort during this study. 


\section{Reference}

01. Arshad AS, Hamid S, Jabeen R, Anjum F. Measuring patient satisfaction- a cross sectional study to improve quality of care at a tertiary care hospital. Healthline J Indian Assoc Prevent Soc Med. 2012;3(1)59-62.

[Crossref]

02. Ibrahim A, Chompikul J, Isaranurug S. Patient Satisfaction with Health Services at the Outpatient Department of Indira Gandi Memorial Hospital. Amale' Maldives Mahidol University. 2008.

[Crossref]

03. Ofili OU. Patient satisfaction in healthcare delivery-a review of current approaches and methods. European Scientific J. 2014;10(25)1857-7881.

doi: 10.19044/esj.2014.v10n25p\%25p [Crossref]

04. Qadri SS, Pathak R, Singh M, Ahluwalia S, Saini S, Garg P. An assessment of patients satisfaction with services obtained from a tertiary care hospital in rural Haryana. International Journal of Collaborative Research on Internal Medicine and Public Health. 2012;4(8)1523-1537.

[Crossref]

05. Dayasiri M, Lekamge E. Predictors of patient satisfaction with quality of health care in Asian hospitals. Australasian Med J. 2010;3(11)739.

doi 10.4066/AM].2010.375 [Crossref]

06. Guirguis WW, Mokhtar S, Al-Torkey M, Khalaf A. Patient satisfaction with hospital services: determinants and level in a hospital in Kuwait. J Egypt Public Health Assoc. 1992;67(1-2)87-108. [Crossref]

07. Biderman A, Carmel S, Yeheskel A. Measuring patient satisfaction in primary care- a joint project of community representatives, clinic staff members and a social scientist. Family practice. $1994 ; 11$ (3)287-291.

doi: $10.1093 /$ fampra/11.3.287 [Crossref]

08. Al-Eisa IS, Al-Mutar MS, Radwan MM, Al-Terkit AM, Al-Eisa I. Patients' satisfaction with primary health care services at capital health region, Kuwait. Middle East J Family Med. 2005;3(3)1016.

[Crossref]
09. Al Doghaither A. Inpatient satisfaction with physician services at king khalid university hospital, riyadh, saudi arabia. East Mediterr Health J. 2004;10(3)358-364.

Available at: [Article] [Crossref]

10. Mohd A, Chakravarty A. Patient satisfaction with services of the outpatient department. Med J Armed Forces India. 2014;70(3)237-242.

doi: $\quad 10.1016 /$ j.mjafi.2013.06.010 [Crossref]

11. Bodur S, Özdemir YE, Kara F. Outpatient satisfaction with health centers in urban areas. Turkish J Med Sci. 2002;32(5)409-414. [Crossref]

12. Dey DK, Mishra V. Determinants of choice of healthcare services utilization- empirical evidence from India. Indian $\mathrm{J}$ Comm Health. 2014;26(4)356-363.

[Crossref]

13. Margolis SA, Al-Marzouqi S, Revel T, Reed RL. Patient satisfaction with primary health care services in the United Arab Emirates. Int J Quality Health Care. 2003;15(3)241-249.

doi: 10.1093/intqhc/mzg036 [Crossref]

14. Senarath U, Gunawardena NS, Sebastiampillai B, Senanayake A, Lekamge S, Seneviratna A, et al. Patient satisfaction with nursing care and related hospital services at the National Hospital of Sri Lanka. Leadership in Health Services. 2013;26(1)63-77.

doi: $10.1108 / 17511871311291732$ [Crossref]

15. Hansen PM, Peters DH, Viswanathan K, Rao KD, Mashkoor A, Burnham G. Client perceptions of the quality of primary care services in Afghanistan. International journal for quality in health care. $2008 ; 20(6) 384-391$.

doi: $10.1093 /$ intqhe/mzn040 [Crossref]

16. Sodani $\mathrm{P}$, Sharma K. Assessing patient satisfaction for investigative services at public hospitals to improve quality of services. Nat J Com Med. 2011;2(3)404-408.

[Crossref]

17. Singh S, Kaur P, Rochwani R. Patient satisfaction levels in a tertiary care medical college hospital in Punjab, North India. Int $\mathrm{J}$ Res Dev Health. $2013 ; 1(4) 172-182$.

[Crossref] 